\title{
B Corp in het Nederlandse vennootschapsrecht anno 2019 nog een storm in een glas water
}

\author{
Mr.R.L.Pouwer*
}

\begin{abstract}
De komst van Beneficial Corporations, of kortweg B Corps, naar Nederland roept vragen op. Wat is een B Corp? Hoe kun je een B Corp worden en blijven? En wat zijn de gevolgen van een certificering als B Corp in het Nederlandse vennootschapsrecht? Deze bijdrage beschrijft de B Corps en de kaders waarbinnen zij opereren.
\end{abstract}

\section{Inleiding}

Wat hebben Ben \& Jerry's en Tony's Chocolonely met elkaar gemeen? Bonte verpakkingen, veel cacao en een hoog verslavingsrisico. Maar er is meer. Ook vanuit juridisch perspectief vertonen Ben \& Jerry's en Tony's Chocolonely gelijkenissen. Beide ondernemingen zijn namelijk gecertificeerde Beneficial Corporations, of kortweg B Corps. Deze van oorsprong Amerikaanse certificering is inmiddels ook overgewaaid naar ons kikkerland.

B Corps zijn for-profit bedrijven die uitdrukkelijk oog hebben voor de belangen van alle stakeholders van de vennootschap. Denk bijvoorbeeld aan de Nederlandse B Corps Dopper, Fairphone, SnappCar en Triodos Bank. Binnenkort kan het beursgenoteerde voedingsmiddelenconcern Wessanen aan dit rijtje worden toegevoegd. De algemene vergadering van Wessanen besloot namelijk op 11 april van dit jaar tot een statutenwijziging ter implementatie van de certificering als B Corp. ${ }^{1}$

De opmars van B Corps in het Nederlandse vennootschapsrecht roept verschillende vragen op. In deze bijdrage wordt aangevangen met een beschrijving van de karakteristieken van een B Corp en het certificeringsproces. Vervolgens wordt een aantal relevante kaders waarbinnen B Corps opereren onderzocht om tot beantwoording van de vraag te komen of een B Corp anno 2019 in het Nederlandse vennootschapsrecht een orkaan veroorzaakt of dat het een storm in een glas water is.

Mr. R.L. Pouwer werkt als Corporate Governance Analyst bij De Brauw Blackstone Westbroek te Amsterdam.

1. Website Investors Relations Koninklijke Wessanen N.V., AGM 11 april 2019 Voting Results. Zie: https://wessanen.com/investor-relations/ shareholders/agm-agenda-and-minutes.

\section{Wat is een B Corp?}

2.1 Een vennootschap met een winstoogmerk ...

Een B Corp ${ }^{2}$ is een vennootschap met een winstoogmerk die privaat als B Corp is gecertificeerd. Het is dus géén bijzondere rechtsvorm en het is géén non-gouvernementele organisatie. Een B Corp dient geen puur maatschappelijk belang en is evenmin financieel afhankelijk van of opgericht door de overheid. Kort en goed: een B Corp is een bedrijf dat winst wil maken.

Een B Corp kan beursgenoteerd zijn. Er zijn verschillende voorbeelden van B Corps die als zodanig naar de beurs zijn gegaan (bijvoorbeeld Laureate Education aan Nasdaq) en vennootschappen die een B Corp zijn geworden terwijl hun aandelen op de beurs werden verhandeld (bijvoorbeeld Natura\&Co aan Novo Mercado). ${ }^{3}$ Recentelijk heeft in Nederland het sinds 1959 aan Euronext Amsterdam genoteerde Koninklijke Wessanen N.V. de eerste stappen naar een certificering als B Corp gezet. ${ }^{4}$

\section{2 ... die alle belanghebbenden wenst te bevoordelen}

Wat B Corps onderscheidt van andere for-profit-bedrijven is dat zij zich vrijwillig en ondubbelzinnig committeren aan normen op het gebied van transparantie, maatschappelijke verantwoordelijkheid en duurzaamheid. Dit doen zij in hun statuten, in hun bedrijfsvoering en beleid en door middel van publiekelijke verantwoording en rapportage. $^{5}$

Een B Corp gebruikt behaalde winst als middel om op lange termijn alle belanghebbenden van de vennootschap te

2. De B Corp-certificering is een vorm van private certificering die uitdrukkelijk dient te worden onderscheiden van de Benefit Corporation, de in een deel van de Amerikaanse Staten erkende rechtsvorm. Zie: https:// benefitcorp.net/businesses/benefit-corporations-and-certified-b-corps? $\mathrm{ga}=2.166605950 .1130060772 .1560775701-1798584194.1560775701$.

3. FAQs about Public Companies and B Corp Certification. Zie: https:// blab-mktg-bcorporation-production.s3.amazonaws.com/FAQ_Public_ Companies_and_B_Corp_Certification.pdf.

4. Website Investors Relations Koninklijke Wessanen N.V., Corporate Governance. Zie: https://wessanen.com/investor-relations/corporategovernance.

5. Website B Lab. Zie: https://bcorporation.net/about-b-corps. 


\section{Maandblad \\ Ondernemingsrecht}

bevoordelen. ${ }^{6}$ Van aandeelhouders, leveranciers en klanten tot werknemers, maatschappelijke groeperingen en het klimaat. De belangen van deze stakeholders zijn expliciet onderdeel van het kader waarbinnen de vennootschap en haar organen opereren en de verantwoordelijkheden die zij dragen. En dat allemaal onder het adagium 'We envision a global economy that uses business as a force for good'.?

\section{Hoe word en blijf je een B Corp?}

\subsection{B Lab}

De certificering van vennootschappen als B Corp (B Certificering) is een initiatief van het in 2006 opgerichte B Lab. Deze van oorsprong Amerikaanse non-profitorganisatie wordt privaat gefinancierd door eigen inkomsten en donaties. ${ }^{8} \mathrm{~B}$ Lab houdt zich wereldwijd bezig met het ontwikkelen, toekennen en controleren van B Certificeringen. ${ }^{9}$ Op de website van B Lab is alle relevante informatie omtrent het certificeringsproces te vinden. Welke hordes moet een Nederlandse vennootschap nemen om haar weg als B Corp te vervolgen?

\subsection{Stap 1: B Impact Assessment}

Allereerst moet de vennootschap online het door B Lab ontwikkelde B Impact Assessment (BIA) maken. Het BIA brengt in kaart hoe de vennootschap omgaat met de belangen van verschillende stakeholders. De toetsing ziet op vijf deelgebieden: governance, werknemers, klanten, milieu en (lokale, nationale en mondiale) gemeenschappen waarin de vennootschap opereert. Het ontwikkelen van en toezichthouden op het BIA valt onder de verantwoordelijkheid van B Labs zogenoemde Standards Advisory Council. ${ }^{10}$

De ingevulde BIA dient door de B Corp in spe zo veel mogelijk te worden ondersteund met schriftelijke toelichting, voorbeelden, handleidingen, implementatietools en beleidsdocumenten. Op basis hiervan worden punten toegekend op een schaal van nul tot tweehonderd. Om in aanmerking te komen voor een B Certificering dienen minimaal tachtig punten te worden behaald. ${ }^{11}$ Vervolgens verifieert, valideert en beoordeelt B Lab de behaalde score. Dit doet zij eerst schriftelijk en vervolgens mondeling. Gedurende een telefoongesprek worden de antwoorden op de vragen en de ondersteunende documenten met de vennootschap besproken. ${ }^{12}$

B Certificering is in beginsel ontworpen om een vennootschap in haar geheel te beoordelen. Dit betekent dat in beginsel ook de activiteiten van de dochterondernemingen van de

6. The B Corp Declaration of Interdependence.

7. The B Corp Declaration of Interdependence.

8. Website B Lab. Zie: https://bcorporation.net/about-b-lab/funders-andfinances.

9. R. Honeyman \& J. Tiffany, The B Corp Handbook, Oakland: BerrettKoehler Publishers, Inc. 2019, p. 221.

10. Website B Lab. Zie: https://bcorporation.net/about-b-lab/standardsand-governance.

11. Honeyman \& Tiffany, p. 61-63, 170 .

12. Honeyman \& Tiffany, p. 61-63, 171 . vennootschap in het certificeringsproces worden meegenomen. Om een volledig concern te certificeren, dient elk van de dochterondernemingen apart een B Certificering aan te vragen en te verkrijgen. Ook kan een gezamenlijke aanvraag worden ingediend voor alle entiteiten van het concern. In dat geval moet het BIA minimaal met een gemiddelde score van tachtig worden volbracht. Het is echter ook mogelijk om alléén voor een dochtervennootschap een B Certificering te verkrijgen. Zo is Ben \& Jerry's een B Corp, maar haar moedervennootschap Unilever niet. ${ }^{13}$

\subsection{Stap 2: Agreement for B Corporation Certification} Vervolgens tekent de vennootschap de Agreement for B Corporation Certification (B Agreement) met B Lab. Hierin worden praktische zaken geregeld, zoals de jaarlijks te betalen toeslag, intellectuele-eigendomsrechten, transparantie- en publicatievereisten en afspraken over het voorzetten en het beëindigen van de certificatie. ${ }^{14}$ Ook worden afspraken vastgelegd over het nastreven van de waarden en ambities van B Corps. Zo tekent de vennootschap de $B$ Corp Declaration of Interdependence als symbool van haar inzet om de gezamenlijke doelen van B Corps te halen. ${ }^{15}$ De tekst van de verklaring luidt als volgt:

'We envision a global economy that uses business as a force for good. his economy is comprised of a new type of corporation - the $\mathrm{B}$ Corporation - Which is purpose-driven and creates benefit for all stakeholders, not just shareholders. As B Corporations and leaders of this emerging economy, we believe that we must be the change we seek in the world, that all business ought to be conducted as if people and place mattered, that, through their products, practices, and profits, businesses should aspire to do no harm and benefit all and to do so requires that we act with the understanding that we are each dependent upon another and thus responsible for each other and future generations. ${ }^{16}$

\subsection{Stap 3: Publicatie}

In het kader van transparantie wordt over elke B Corp algemene informatie op de website van B Lab geplaatst. Verder wordt op de website het BIA-rapport openbaar gemaakt. Dit betreft een samenvatting van de door de B Corp behaalde score op elk van de vijf categorieën. ${ }^{17}$ Als de B Corp een meerderheidsaandeelhouder heeft, wordt deze tevens vermeld. ${ }^{18}$

\subsection{Stap 4: Statutenwijziging}

In de B Agreement verplicht de B Corp zich om binnen negentig dagen na het tekenen van de B Agreement in de sta-

13. Website B Lab. Zie: https://bcorporation.net/certification/relatedentities.

14. B Corp Certification Best Practices Guide, p. 3.

15. Honeyman \& Tiffany, p. 171. Zie tevens: Agreement for B Corporation Certification, p. 9.

16. The B Corp Declaration of Interdependence, beschikbaar via de website van B Lab. Zie: https://bcorporation.net/about-b-corps.

17. B Corp Certification Best Practices Guide, p. 4.

18. Agreement for B Corporation Certification, p. 2. 
tuten te verankeren dat zij de impact van haar handelen op alle stakeholders afweegt. ${ }^{19}$ Er zal dus een statutenwijziging plaats moet vinden..$^{20}$ Allereerst dient de statutaire doelstelling van de vennootschap te bepalen dat het 'een van de doelen van de vennootschap is door middel van haar bedrijfsvoering en activiteiten, een significant positieve invloed te hebben op de maatschappij en het milieu in zijn algemeenheid'. ${ }^{21}$

Ten tweede behoren de statuten van de vennootschap over bestuurders te bepalen dat zij bij hun handelen

'ook rekening houden met de sociale, economische, juridische of andere gevolgen van de bedrijfsuitvoering van de Vennootschap ten aanzien van (i) de werknemers, de dochtermaatschappijen en leveranciers (ii) de belangen van de klanten van de Vennootschap en haar dochtermaatschappijen, (iii) de gemeenschappen en de samenleving waarin de Vennootschap, haar dochtermaatschappijen en leveranciers hun bedrijf uitvoeren, (iv) het lokale en globale milieu en (v) de korte en lange termijn belangen van de onderneming.' 22

\subsection{Hoe blijfje vervolgens een B Corp?}

Om de certificering te behouden moet een B Corp allereerst een jaarlijkse toeslag betalen aan B Lab. Daarnaast dient zij om de drie jaar succesvol een BIA te doorlopen. ${ }^{23}$ Een change of control bij een B Corp heeft op zichzelf dan ook geen gevolgen voor de certificering als B Corp. Een verandering in het aandeelhoudersbestand of een bestuurswissel kan natuurlijk wel leiden tot een andere strategie en ander beleid van de vennootschap, waardoor de kans bestaat dat de vennootschap de eerstvolgende BIA niet kan of wil halen. Ook is het mogelijk dat de vennootschap niet meer bereid is de toeslag aan $\mathrm{B}$ Lab te betalen. Zo kan een change of control indirect resulteren in verlies van de certificering als B Corp.

\section{Hoe past een B Corp in het Nederlandse vennootschapsrecht?}

\subsection{Het Nederlandse stakeholdersmodel}

Een B Corp weegt bij beleid- en besluitvorming uitdrukkelijk de belangen van alle belanghebbenden af. Een expliciete toepassing van het stakeholders-model dus. In de Verenigde Staten is de B Corp een big deal, omdat daar het shareholdersmodel leidend is. ${ }^{24}$ Een vennootschap bestaat in de Verenigde Staten van oudsher - kort gezegd - bij de gratie van de behar-

19. Agreement for B Corporation Certification, p. 2. Overigens geldt voor Amerikaanse corporations een termijn van een jaar en voor Amerikaanse Benefit Corporations een termijn van twee jaar.

20. Agreement for B Corporation Certification, p. 2. Zie tevens: website B Lab. Zie: https://bcorporation.net/certification/legal-requirements.

21. B Lab Legal Requirements Tool, beschikbaar via de website van B Lab. Zie: https://bcorporation.net/certification/legal-requirements.

22. B Lab Legal Requirements Tool, beschikbaar via de website van B Lab. Zie: https://bcorporation.net/certification/legal-requirements.

23. Honeyman \& Tiffany, p. 170

24. M.J.G.C. Raaijmakers, Marius geannoteerd, Serie Van der Heijden Instituut nr. 133Deventer: Wolters Kluwer 2016/27.1.2. tiging van haar aandeelhoudersbelangen (shareholder primacy). ${ }^{25}$ Bestuurders en commissarissen van de vennootschap dienen zich primair te richten op het vergroten en beschermen van aandeelhouderswaarde. ${ }^{26} \mathrm{~B}$ Corps zijn dan ook een tegenreactie op dit shareholders-model; de B Corp past vrijwillig en uitdrukkelijk het stakeholders-model toe en legt hier ook verantwoording over af. ${ }^{27}$

In tegenstelling tot het Amerikaanse rechtssysteem kenmerkt Nederlandse corporate governance zich sinds jaar en dag door het stakeholders-model. De vennootschap wordt hier beschouwd als een zelfstandig samenwerkingsverband tussen de verschillende vennootschappelijke organen, waarin de belangen van diverse bij de vennootschap betrokken stakeholders worden afgewogen, ${ }^{28}$ maar waarbij steeds de continuïteit van de vennootschap vooropstaat. ${ }^{29}$ Het primaat rust in Nederland dan ook niet bij het aandeelhoudersbelang. ${ }^{30} \mathrm{Het}$ bestuur dient uitdrukkelijk rekening te houden met de belangen van alle stakeholders van een vennootschap, waaronder maatschappelijke belangen. ${ }^{31}$ De raad van commissarissen behoort bij zijn toezicht op het bestuursbeleid en de algemene gang van zaken van de vennootschap na te gaan of de diverse stakeholders-belangen voldoende in ogenschouw worden genomen. Als dit niet het geval is, wordt van de commissarissen verwacht dat zij proactief optreden. Ook dient de raad van commissarissen alle stakeholders-belangen mee wegen bij het adviseren van het bestuur. ${ }^{32}$

In het algemeen wordt aangenomen dat de aandeelhouders van de vennootschap door middel van de aan hen toegekende bevoegdheden in beginsel hun eigen belangen mogen beharti-

25. Asser/Maeijer, Van Solinge \& Nieuwe Weme 2-II* 2009/127. Zie tevens: M. Lipton e.a., It's Time To Adopt The New Paradigm, Wachtell, Lipton, Rosen \& Katz, februari 2019.

26. P. Atkins e.a., Social Responsibility and Enlightened Shareholder Primacy: Views from the Courtroom and Boardroom, Harvard Law School Forum on Corporate Governance and Financial Regulation, februari 2019, p. 1.

27. Zoals getoetst in het BIA en verankerd in de statuten van de B Corp en de B Agreement.

28. Asser/Maeijer, Van Solinge \& Nieuwe Weme 2-II* 2009/394. Zie tevens: HR 9 juli 2010, ECLI:NL:HR:2010:BM0976 (AMSI), r.o. 4.4.1.

29. B. Kemp in: Aandeelhoudersverantwoordelijkheid (VDHI nr. 129) 2015/3.7. Zie tevens: R. Goodijk, Herwaardering van de Rijnlandse principes, Over governance, overleg en engagement, Assen: Van Gorcum 2008.

30. Recent werd dit nog bevestigd toen de Tweede Kamer een amendement op de voorgestelde implementatiewet van de Aandeelhoudersrichtlijn aannam. Op grond hiervan moeten beursgenoteerde vennootschappen in hun bezoldigingsbeleid en -verslag een toelichting geven op de wijze waarop rekening is gehouden met het maatschappelijk draagvlak. Zie: Gewijzigd wetsvoorstel Implementatie Gewijzigde Aandeelhoudersrichtlijn, Kamerstukken II 2018/19, 35058, p. 3. Zie tevens: Gewijzigd amendement van het lid Snels, Kamerstukken II 2018/19, 35058, nr. 24.

31. Asser/Van Solinge \& Nieuwe Weme 2-IIb 2019/147.

32. Art. 2:140/250 lid 2 BW. Zie: Asser/Van Solinge \& Nieuwe Weme 2-IIb 2019/295. Zie specifiek over dit onderwerp: C.D.J. Bulten \& C.J.H. Jansen, De taak van de commissaris in een duurzame wereld, Ondernemingsrecht 2019/69. 
gen, zogenoemde aandeelhoudersautonomie. ${ }^{33}$ Dit uitgangspunt is in de rechtspraak begrensd door de redelijkheid en billijkheid van artikel 2:8 $\mathrm{BW}^{34}$ en door het uitgangspunt dat aandeelhouders geen misbruik van hun recht mogen maken. ${ }^{35}$ De rol van aandeelhouders is de afgelopen jaren echter steeds verder ingekleurd in wet- en regelgeving, waarbij wel degelijk van aandeelhouders wordt verwacht dat zij de belangen van andere stakeholders in acht nemen. Denk bijvoorbeeld aan de Corporate Governance Code, de bepalingen van de gewijzigde Aandeelhoudersrichtlijn ${ }^{36}$ en de door Eumedion recent vastgestelde Nederlandse Stewardship Code over de rol van institutionele beleggers bij de beursvennootschappen waarin zij beleggen. ${ }^{37}$

Een B Certificering van een vennootschap in Nederland zorgt, in tegenstelling tot een certificering in de Verenigde Staten, in beginsel niet voor een juridische verandering van de vennootschap of van de verantwoordelijkheden van haar organen. Ook niet-B Corps dienen in het Nederlandse vennootschapsrecht immers uitdrukkelijk een scala aan stakeholdersbelangen af te wegen. Dat neemt overigens niet weg dat met de keuze voor een certificering als B Corp de vennootschap publiekelijk haar stakeholdercommitment benadrukt. Dit kan ertoe leiden dat de vennootschap eerder niet-juridisch ter verantwoording wordt geroepen voor haar handelen ten opzichte van de stakeholders-belangen door bijvoorbeeld journalisten of consumenten.

\subsection{Corporate social responsibility}

Een kader waarin B Corps kunnen worden geplaatst, is dat van corporate social responsibility (CSR), ook wel maatschappelijk verantwoord ondernemen genoemd. Het gaat hierbij in de kern om een streven naar de balans tussen milieubelangen (planet), werknemers- en sociale belangen (people) en winstbelangen (profit) van een onderneming. ${ }^{38}$ CSR integreert zo uitdrukkelijk maatschappelijke vraagstukken in de strategie, het beleid en de activiteiten van ondernemingen. ${ }^{39}$

Concreet gaat het bij CSR bijvoorbeeld om het voorkomen van corruptie, van schade aan het klimaat en van het schenden

33. Zie B. Kemp in: Aandeelhoudersverantwoordelijkheid (VDHI nr. 129) 2015/5.2.

34. HR 4 april 2014, ECLI:NL:HR:2014:797. Zie tevens Hof Amsterdam (OK) 3 maart 1999, ECLI:NL:GHAMS:1999:AD3062 (Gucci).

35. HR 30 juni 1944, ECLI:NL:HR:1944:BG9449 (Wennex).

36. Richtlijn (EU) 2017/828 van het Europees Parlement en de Raad van 17 mei 2017 tot wijziging van Richtlijn 2007/36/EG wat het bevorderen van de langetermijnbetrokkenheid van aandeelhouders betreft.

37. Zie voor een uitgebreide behandeling: M.A.J. Cremers \& S. Rietveld, Aandeelhoudersbetrokkenheid van institutionele beleggers bij Nederlandse beursvennootschappen en de Nederlandse Stewardship Code, Tijdschrift voor de Ondernemingsrechtpraktijk 2019/04.

38. Lambooy 2010 , p. 57.

39. De Europese Commissie formuleert CSR in de Green Paper Promoting a European framework for Corporate Social Responsibility als: 'a concept whereby companies integrate social and environmental concerns in their business operations and in their interaction with their stakeholders on a voluntary basis'. Zie: $\operatorname{COM}(2001) 366$. van mensenrechten. ${ }^{40}$ Dit wordt gedreven en verantwoord door een risico- en rendementberekening van de vennootschap, waarbij ook de druk vanuit verschillende stakeholders en het maatschappelijk debat wordt meegenomen. Daarnaast zijn CSR-normen inmiddels verankerd. Denk bijvoorbeeld aan de verboden op discriminatie en omkoping ${ }^{41}$ en de toenemende rapportage- en openbaarmakingsverplichtingen, zogenoemde duurzaamheidsverslaggeving. ${ }^{42}$ En vergeet vooral het groeiend aantal privaat- en publiekrechtelijke gedragscodes, protocollen en standaarden niet. ${ }^{43}$

CSR is een open begrip dat in het beleid en de bedrijfsvoering van een vennootschap op talloze manieren kan worden geïncorporeerd, al dan niet specifiek als zodanig bestempeld. Bij B Corps is CSR steeds aanwezig. Dit wordt immers getoetst in het BIA en is tevens vastgelegd in de B Corp Declaration of Interdependence. Daarnaast gaat een $\mathrm{B}$ Corps nog een stap verder door statutair te verankeren dat zij streeft naar het bereiken van bredere maatschappelijke doelstellingen. Dit wordt ook wel gekwalificeerd als social entrepreneurship. ${ }^{44}$

\subsection{Aansprakelijkheidsrisico's}

Een voor de rechtspraktijk relevante vraag is of de B Certificering van een vennootschap invloed heeft op strafrechtelijke en civiele aansprakelijkheid. ${ }^{45}$ Denkbaar is dat CSR-normen de open zorgvuldigheidsnormen en de redelijkheid- en billijkheidsnormen nader invullen. Een schending van CSR, publieke uitingen over CSR door de vennootschap of juist een ontbreken van CSR of maatschappelijke aspecten zouden bepalende factoren kunnen zijn. ${ }^{46}$ Anno 2019 is dergelijke aanspra-

40. D.G. Szabó, Mandatory Corporate Social Responsibility Reporting in the EU, Portland: Eleven International Publishing 2016, p. 7-9. Zie tevens: Asser/Hartkamp/Sieburg, 2-II* 2009/31.

41. Lambooy 2010, p. 14.

42. Zie Szabó 2016. Een actueel overzicht van gedragscodes, auditprotocollen en standaarden op het gebied van CSR is beschikbaar op www.standardsmap.org/identify.

43. H. Koster, Sustainable finance \& sustainablility reporting, Ondernemingsrecht 2018/49. Zie tevens: A.L. Vytopil \& F.M. Verburg, Implementatie van de Richtlijn Niet-Financiële Informatie in Nederland, Ondernemingsrecht 2016/119. De Europese Commissie benadrukte recentelijk nog dat zij in de transitie naar een duurzame economie een grote rol ziet weggelegd voor ondernemingen en het wet- en regelgevend kader daaromheen. Zie respectievelijk COM(2018) 97 (Action Plan on Financing Sustainable Growth) en COM (2019) 22 (Reflection Paper Towards a Sustainable Europe by 2030).

44. De Europese Commissie formuleert social entrepreneurships als bedrijven 'whose main objective is to have a social impact rather than make a profit for their owners or shareholders. It operates by providing goods and services for the market in an entrepreneurial and innovative fashion and uses its profits to achieve social objectives'. Zie http://ec.europa.eu/ growth/sectors/social-economy/enterprises_en.

45. Denk aan de verscheidene wegen van bestuurders- en commissarissenaansprakelijkheid of twijfel aan een juist beleid of een juiste gang van zaken (art. 2:350 BW), dan wel wanbeleid in geval van een enquêteprocedure (art. 2:355 e.v. BW).

46. S. Meijer, F. Vermeulen \& C. Vreede in: Sustainability and financial markets, Deventer: Wolters Kluwer 2019, hoofdstuk 5. 


\section{Maandblad}

kelijkheid echter nog niet aangenomen ${ }^{47}$ en in het algemeen geldt het uitgangspunt dat grote terughoudendheid is gepast bij de toetsing van CSR-normen. ${ }^{48}$ Het risico op een aansprakelijkheid wordt echter wel groter in het huidige tijdsbeeld, ${ }^{49}$ waarin wereldwijd steeds meer rechtszaken aanhangig worden gemaakt voor het aansprakelijk stellen van bedrijven voor schade aan de maatschappij. ${ }^{50}$ Een actueel voorbeeld in Nederland is de rechtszaak die Milieudefensie is begonnen om Shell aansprakelijk te stellen voor 'haar substantiële bijdrage aan klimaatverandering en voor de schade die Shell daardoor aanricht aan de samenleving en het milieu' ${ }^{51}$

Wanneer aansprakelijkheid voor het niet in acht nemen van maatschappelijke belangen of de schending van CSR-normen zich daadwerkelijk voordoet, dan zou dit mogelijk eerder bij B Corps kunnen worden aangenomen dan bij niet-B Corps. De expliciete verankering van stakeholders-belangen in de statuten van B Corps en hun uitdrukkelijke communicatie en rapportage hierover zouden in de rechtszaal een rol kunnen spelen bij de invulling van de zorgvuldigheid die van (een orgaan van) de vennootschap wordt verwacht. De verankering van fiduciaire verplichtingen en verantwoordelijkheden bij B Corps kan een concreet startpunt zijn om te na te gaan of zorgvuldig is gehandeld.

\section{B Corp anno 2019 is storm in het Nederlandse vennootschappelijke glas water}

Wat hebben Ben \& Jerry's en Tony's Chocolonely met elkaar gemeen? Beide zijn gecertificeerd als B Corp, een private certificering die de laatste jaren met de westenwind vanuit de Verenigde Staten is overgewaaid. B Corps zijn for-profitondernemingen die zich vrijwillig en expliciet richten op het behalen van maatschappelijke doelstellingen. B Corps wegen uitdrukkelijk een scala aan belangen af en passen zo het stakeholders-model toe. Niets spectaculairs in ons huidige systeem van corporate governance, waarin de vennootschap en haar organen de belangen van alle stakeholders af dienen te wegen. In het Nederlandse vennootschapsrecht is een B Corp anno 2019 dan ook een storm in een glas water.

47. Voor de reikwijdte van dit artikel gaat een gehele bespreking van aansprakelijkheid voor het schenden van CSR-normen te ver. Zie voor een uitgebreide behandeling: L.F.H. Enneking e.a., Zorgplichten van Nederlandse ondernemingen inzake internationaal maatschappelijk verantwoord ondernemen. Een rechtsvergelijkend en empirisch onderzoek naar de stand van zaken van het Nederlandse recht in het licht van de UN Guiding Principles, Den Haag: Boom Juridische uitgevers 2016, A.L. Vytopil, Contractual Control in the Supply Chain On Corporate Social Responsibility, Codes of Conduct, Contracts and (Avoiding) Liability, Den Haag: Eleven Legal Publishers 2015 en C. van Dam, Onderneming en mensenrechten. Zorgvuldigheidsnormen voor ondernemingen ter voorkoming van betrokkenheid bij schending van mensenrechten (oratie Universiteit Utrecht), Den Haag: Boom Juridische uitgevers 2008.

48. Asser/Van Solinge \& Nieuwe Weme 2-IIb 2019/147. Zie tevens: Van Schilfgaarde e.a., Van de BV en de NV, Deventer: Kluwer 2017/5.

49. Meijer, Vermeulen \& Vreede 2019, p. 36, 39.

50. Meijer, Vermeulen \& Vreede 2019, p. 27, verwijzend naar het onderzoeksrapport 'Global trends in climate change legislation and litigation', beschikbaar via http://archive.ipu.org/pdf/publications/global.pdf.

51. Openbare brief Milieudefensie aan Royan Dutch Shell plc d.d. 4 april 2018, zie: https://milieudefensie.nl/actueel/aansprakelijkstelling-shell. 